\title{
Editorial da seção - 0 estudo das relações entre práticas sociais e representações: retomando questões
}

\author{
Pedro Humberto Faria Campos ${ }^{1}$
}

Uma das grandes questões abertas atualmente no campo de estudo da Teoria das Representações Sociais é o das relações entre as práticas sociais desenvolvidas por um determinado grupo social e seus pensamentos (processos e conteúdos incluídos) coletivos. A questão não é nova, entretanto o modo de estudar as RS constitui ainda um grande desafio para os psicossociólogos de várias orientações, porque implica a assimilação de dados de natureza cognitiva e dados de natureza comportamental. $O$ interesse no estudo das representações sociais reside no fato que, dada sua natureza de conhecimento socialmente gerado e socialmente partilhado, as representações sociais produzem duas consequências:

- Uma vez instalada, estabelecida por um determinado grupo social, uma dada representação resiste à mudança, resiste às mudanças do meio social, salvo nas condições onde estas transformações são drásticas e atacam o núcleo central das representações;

- As representações sociais funcionam como uma norma social (corolariamente como norma grupal, com seus efeitos de conformidade, nos casos de maiorias nômicas e seus efeitos de inovação, nos casos de maiorias anômicas) autorizando o que é considerado como "obrigatório" para se definir o objeto ou se relacionar com ele, o que é "comum" (frequente), "eventual" (excepcional) e o que é "inaceitável", "anormal" (contra a norma do grupo para o objeto em questão).

As representações sociais permitem ainda um conhecimento implícito, quase intuitivo, da parte dos sujeitos acerca do caráter normativo ou contra normativo de um tipo de comportamento ou de um tipo de julgamento. Neste sentido, pode-se também afirmar que toda representação social tem implicações éticas, em termos do que pode ou o que deve, e o que não pode ou não deve ser feito em determinadas situações, face a determinados objetos.

O tema das relações entre práticas sociais e representações sociais não é novo. Desde a retomada do interesse pela TRS, em meados dos anos 80 , multiplicam-se os estudos que visam, direta ou indiretamente, a compreensão das práticas pela via das representações sociais. Como pode ser exemplificado pelo vasto conjunto de estudos sobre a representação social do trabalho docente. As relações de influência são complexas, sendo necessário, atualmente delinear sob quais condições, são as práticas que determinam as representações sociais e sob quais outras condições ocorre o inverso. $O$ estado atual da teoria nos mostra que três condições afetam a relação entre as práticas e as representações: a) a percepção que os sujeitos têm da situação como sendo reversível ou irreversível; b) o grau de autonomia dos sujeitos face cada situação específica; c) por fim, o grau de ativação das cargas afetivas mobilizadas, tendo como referência a memória coletiva.

\footnotetext{
${ }^{1}$ Doutor em Psicologia Social. Docente permanente no Programa de Pós-graduação em Educação da Universidade Estácio de Sá - Rio de Janeiro, RJ, Brasil. Colaborador do Programa de Pós-graduação em Psicologia na Pontifícia Universidade Católica de Goiás - Goiânia, GO, Brasil. E-mail: pedrohumbertosbp@terra.com.br.
} 
Os trabalhos anteriores nos ajudaram a reforçar o interesse pelo estudo do que chamamos (Campos, 2003) de "Situações Sociais Complexas". Embora o adjetivo "complexo" possa ser considerado adereço, uma vez que toda situação social implica em um elevado grau de complexidade de interação entre os diferentes atores sociais, insistimos em sua aplicação na expressão proposta para colocar em evidência o modo como as representações sociais participam na emergência, realização e julgamento das práticas. Nas situações reais, os sujeitos raramente se deparam com um objeto isolado e raramente se ancoram em uma única representação para identificar a situação, avaliar as condutas possíveis e agir. Dito de outro modo: um professor não regula sua ação frente a um aluno baseado exclusivamente na representação social do "mau-aluno" ou do "bom-aluno", suas práticas resultam de uma equação bem mais complexa que inclui, minimamente, as representações do papel de professor, do aluno (bom ou mau), da escola, do contexto (de escola em bairro favorecido ou em bairro desfavorecido, por exemplo) etc. Assim, nas situações sociais de interação entre dois agentes (seja a interação concreta ou simbólica), os sujeitos constroem uma "Representação Global da Situação" (Codol, 1972, 1974), composto, no mínimo de quatro componentes, a saber, as representações sociais de si mesmo, dos outros, da tarefa e do contexto imediato. Segundo nossa formulação, os sujeitos constroem "Sistemas Representacionais" complexos para fazer frente às situações sociais mais complexas, como a das práticas profissionais, das situações de exclusão ou como o comportamento no trânsito, por exemplo.

Nestes sistemas, as práticas reais, efetivas, são incorporadas como formas cognitivas pré e pós-ato, tanto no sentido da orientação das ações futuras, como do julgamento (avaliação) dos atos emitidos.

Uma interrogação se impõe aos pesquisadores que adotam, em particular a TRS. Poderia esta "teoria", sem o aporte conjunto de outras teorias das ciências sociais, explicar a complexidade da interação entre o pensar e o agir dos grupos sociais? De minha parte, prefiro colocar a questão sob outra formulação. Tomemos um procedimento padrão de pesquisa (um padrão hipotético) para estudar uma RS. Uma breve esquematização pode ser útil aqui: a) delimita-se um objeto, por exemplo, a RS do professor, do enfermeiro, da aids ou do trabalho docente; b) seleciona-se um grupo de sujeitos envolvidos com o objeto e acerca do qual seria interessante conhecer sua RS; c) definem-se algumas estratégias de investigação, das quais se obtém um instrumento, um local, forma de aplicação, técnicas de análise (quantitativas ou qualitativas); d) recolhe-se um conjunto de significados, um conjunto de conteúdos que são significativos, mais ou menos consensuais para o grupo estudado, eventualmente, também é colhido um conjunto de relações entre estes mesmos significados. Então diz-se: aqui está a "RS do objeto X" elaborada pelos sujeitos escolhidos.

Um tal procedimento básico-hipotético poderia ser considerado um estudo de RS? Ele restituiria ou comporia um "olhar psicossocial", uma vez que foi adotada a TRS que é uma "teoria psicossocial"? Poderíamos, nós pesquisadores que nos apoiamos na TRS, nos isentar de olhar para as dinâmicas no campo social do objeto de uma representação que se define como "social"? Uma RS é uma formação simbólica, um conjunto organizado de significados, saberes, crenças ou cognemas; formação gerada na interação de um grupo com um objeto (fenômeno, evento), dentro do campo social que recobre este mesmo objeto, no qual se encontram outras formações simbólicas (ideologias, valores, normas, outras representações sociais, mitos, conhecimentos científicos etc), outros objetos, instituições e, para simplificar, outros grupos sociais com seus valores, crenças etc. Esta visão já estava bem constituída 
desde os primeiros textos sobre a TRS (Moscovici, 1976/1961; Jodelet, 1984), esboçada naquilo que se chamou de "ancoragem".

Para permanecer fiel ao olhar psicossocial da teoria em questão, um procedimentopadrão de investigação deveria comportar ao menos dois "estudos": o estudo das representações sociais como um conjunto organizado de significados que um grupo atribui a um objeto (assim seriam os significados que os professores atribuem ao trabalho docente); e um estudo do contexto, ou da dinâmica do contexto no qual esta RS emerge e tem funcionalidade, marcando a identidade do grupo e regulando suas práticas.

Queremos, desde já, introduzir a definição do que entendemos por práticas sociais, para não deixar margem de dúvida. Na perspectiva de estudar as situações sociais reais, uma fórmula mais exata de definir as práticas sociais é concebê-las como "sistemas de ação socialmente estruturados e instituídos em relação com os papéis" (Abric, 1994), ou ainda como "conjuntos de condutas finalizadas pelos e para os grupos" (Moliner, 2001). Assim, a noção de prática teria como referência básica a ação, o agir dos grupos; e, a ação comporta, então, necessariamente três componentes, o comportamental, o afetivo e o cognitivo. E é isto que nos permite certa legitimidade em estudar a ação, também através de instrumentos de natureza cognitiva.

Dois pontos devem ser destacados: ações ou comportamentos não podem ser estudados separados de um "sistema de ação", na verdade, "sistema ação-representação". O segundo aspecto é que as práticas são construções dos grupos que tem um caráter "instituído", ou seja, tem existência no grupo em suas normas formais ou informais, mas explícitas; e, existe uma relação entre os papéis sociais (determinados pelas instituições ou pelos próprios grupos) e as práticas sociais. Em alguns casos (crises, processos de mudança, conflitos) as práticas podem se opor ou distanciar dos papéis.

O estudo de Guimelli (1994) sobre a "função de enfermeiro" na França é um exemplo da relação entre práticas e papéis. Apresentamos suscintamente:

a) A profissão de enfermeiro era parte do "saber médico », dependente deste saber.

b) O avanço das práticas e tentativas de teorização resulta no reconhecimento oficial da profissão, em 1978; porém, em 1984, uma atualização da legislação faz o inventário dos atos profissionais e identifica um conjunto de atos mais complexos, diversificados, caracterizando um "papel próprio", ou seja, um papel profissional independente do saber médico. Pode-se, então, falar de dois papéis: o "papel tradicional", com tarefas/atos prescritos pelos médicos e o "papel próprio", independente.

c) Com a ajuda de um grupo de enfermeiros experientes e de referência, obtémse uma primeira lista de doze atos (práticas) características do papel próprio.

d) Na primeira etapa da pesquisa, participam 40 enfermeiros diplomados, dicotomizados segundo os tipos de serviços onde atuavam, um tipo caracterizado pela nãoaplicação de tarefas "próprias" e o outro tipo pela possibilidade de aplicar com frequência as práticas deste papel, ou seja, "novas práticas".

e) Para se certificarem da dicotomia, inicialmente projetada pelo tipo de serviço, é aplicado um questionário, com doze questões, perguntando a frequência com que executam cada uma das doze práticas do "papel próprio"; constituindo assim dois grupos: um sem experiência de novas práticas e o outro com real acesso à realização de novas práticas. 
f) Um estudo exploratório foi realizado para identificar uma lista de práticas tanto do "papel prescrito" (tradicional), quanto do "papel próprio"; a partir desta base são utilizados 15 especialistas (enfermeiros de referência) para separarem 10 práticas prescritas e 10 próprias.

g) A lista de 20 compõe uma questão de caracterização, na qual se solicita aos sujeitos para selecionarem os itens que mais caracterizam, na visão (concepção) deles, o papel profissional de enfermeiro. Uma análise de similitude foi aplicada sobre os resultados.

Enfim, os resultados mostram que os dois grupos de fato constituem duas representações distintas, independente dos sujeitos estudarem os dois "papéis" em sua formação. Segundo o autor, são observadas diferenças na estrutura da representação social do papel de enfermeiro, determinadas pelo acesso ou não à realização de prática associadas ao papel próprio.

Este exemplo, ao mesmo que tempo que indica a necessidade de distinguir o papel social (determinado pelas instituições envolvidas) e as práticas reais dos sujeitos em relação ao objeto de representação, nos coloca em uma delicada situação de pesquisa: com as constantes mudanças nas instituições, com o impacto das mídias e da internet e suas redes, e, às vezes, profundas reformas nas políticas públicas, qual ou quais papéis hoje estão constituídos com base nas profissões e instituições com as quais interagimos?

Por fim, os trabalhos que discutimos acima e que agora apresentamos neste número especial, visam a evidenciar que a contribuição da teoria das representações sociais consiste em demonstrar que o ator social (indivíduo ou grupo) constrói um sistema cognitivo capaz de dar coerência, capaz de dar sentido à situação percebida e aos comportamentos empreendidos. Embora o problema se formule em termos de "representações e práticas", ele se coloca também em termos de uma "visão psicossocial", ou um "olhar psicossocial", que visa contribuir para a compreensão das relações (em especial relações de "influência" ou de determinação) entre as ações dos grupos e dos coletivos e suas crenças, mitos, ou outras modalidades de pensamento social. No nosso caso específico, tratar a distinção clara entre papéis e práticas, dentro de um sistema de representações, que funda o sistema sóciocognitivo que regula as condutas, são postulados da teoria. Cabe a nós refletir se isto (a TRS) pode ser útil ao estudo dos grupos sociais e sua vida no mundo social.

Neste cenário, o primeiro artigo que compõe este número especial, "Representações sociais e práticas corporais de rejuvenescimento para mulheres de meia-idade" de Adriana de Aguiar, Brigido Vizeu Camargo e Andrea Barbará da Silva Bousfield, apresenta uma pesquisa que discute a relação entre a representação social do rejuvenescimento e as práticas corporais, através da análise de atitudes, crenças e normas sociais. No segundo artigo apresentado, "Representações sociais e práticas em escolas do ensino fundamental: efeitos de unidades de polícia pacificadora (UPP) no Rio de Janeiro", Rita de Cássia Pereira Lima e Ivan Soares dos Santos partem da divisão dos sujeitos em três grupos distintos, conforme suas práticas escolares tenham relação direta ou não com uma UPP, assim encontram imagens do objeto (UPP) bem distintas e influenciadas pelos contextos de interação efetiva ou não com policiais neste tipo específico de prática que é o "policiamento de vizinhança".

Em um campo bem distinto, Érica Nayla Harrich Teibel e Daniela Barros da Silva Freire Andrade, mostram como as representações de infância elaboradas por profissionais com diferentes áreas de formação, atuantes em uma enfermaria pediátrica, influenciam suas 
práticas cotidianas de cuidado, ou seja, como as representações de infância têm impacto sobre como cada profissional concebe e realiza as atividades na atenção direta às crianças, em artigo intitulado "Intervenção em práticas de cuidado à criança no contexto hospitalar: representações sociais da equipe de saúde". O quarto artigo desta série, "Envelhecimento e representações sociais sobre a participação política em Portugal e no Brasil", de Miriam Cabrera Corvelo Delboni, Silvia Virginia Coutinho Areosa, Paula Cristina Cadima Remoaldo e Maria Clara Costa Oliveira, realiza uma comparação entre as representações sociais do envelhecimento e as práticas de participação ou não-participação na cena política que são associadas à população nesta faixa etária e apontam diferenças substanciais nesta relação práticas/representações em sujeitos dos dois países.

$\mathrm{Na}$ quinta pesquisa aqui publicada, "Perfil de drogadição e práticas sociais entre moradores de rua", as autoras Lila Spadoni, Cilas Pereira Machado Júnior, Letícia Houston Mamede Barroso, Ana Luiza Boni, Margareth Regina Gomes Veríssimo de Faria e Sandra Maria Brunini de Souza mostram como as imagens dos diferentes tipos de drogaditos representados se formam à base de uma espécie de inventário de práticas específicas conforme as drogas supostamente consumidas, como que criando um estereótipo dos "diferentes tipos de drogados" conforme as "práticas" ou usos.

\section{Referências}

Abric, J.-C. (1994a). L'organisation interne des représentations sociales : système central et système périphérique. In: C. Guimelli (Ed.). Structures et transformations des représentations sociales (pp. 73-84). Neuchâtel: Delachaux et Niestlé.

Abric, J.-C. (1994b). Pratiques sociales et représentations. Paris: Presses Universitaires de France.

Abric, J.-C. (1998). A Abordagem estrutural das representações sociais. In A. S. P. Moreira \& D. C. Oliveira (Orgs.). Estudos interdisciplinares de representação social (pp. 27-46). Goiânia, AB Editora.

Campos, P. H. F. (2003). Rapports entre pratiques et représentations: apports théoriques et empiriques pour un modèle d'étude. Psychologie et Société, 6, 3(2), 132-162.

Codol, J.-P. (1972). Représentations et comportements dans les groupes resteints. Thèse de Doctorat en Psychologie Sociale. Université de Provence, Aix-en-Provence.

Codol, J.-P. (1974). On te system of representations in a group situation. European Journal of Social psychology, 4, 343-365.

Flament, C. (1994a). Structure, dynamique et transformation des représentations sociales. In J.-C. Abric (Ed.). Pratiques sociales et représentations. Paris : PUF.

Flament, C. (1994b). Aspects péripheriques des représentations sociales. In: C. Guimelli (Éd.). Structures et transformations des représentations sociales (pp. 85-118). Lausanne: Délachaux et Niestlé.

Guimelli, C., (1994). La fonction d'infirmière : pratiques et représentations sociales. In: J. C. Abric (Éd.).

Pratiques et représentations sociales (pp. 83-108). Paris, PUF.

Jodelet, D. (1984). Représentation sociale : phénomènes, concept et théorie. In: S. Moscovici (Ed.). Psychologie Sociale (pp.357-389). Paris : PUF.

Moliner, P. (2001). La dynamique des représentations sociales. Grenoble : PUG.

Moscovici, S. (1976/1961). La psychanalyse, son image et son public. Paris: PUF.

Moscovici, S. (2003). Por que estudar representações sociais em psicologia? Vida e Saúde, 30(1), 11-30. 